\title{
TEM Characterization of HSLA Steels and Welds
}

\author{
Babak Shalchi Amirkhiz ${ }^{1}$, Dong-Yeob Park ${ }^{2}$, Catherine Bibby ${ }^{1}$ and Pei Liu ${ }^{1}$ \\ 1. CanmetMATERIALS / Natural Resources Canada, Hamilton, Canada \\ 2. CanmetMATERIALS / Natural Resources Canada, Calgary, Canada
}

Characterization of steel microstructure has always been considered challenging when it comes to transmission electron microscopy (TEM). There are a number of reasons behind that, such as magnetism, difficulty of TEM sample preparation, inherent complexity of the structure and the usual high density of dislocations. The microalloyed high strength low alloy (HSLA) steels are an important class of high strength steels extensively used in the pipeline industry. What gives the microalloyed steels their extra strength is the addition of elements such as $\mathrm{Ti}, \mathrm{Nb}$ and $\mathrm{V}$ which can refine the microstructure by forming carbo-nitride precipitates of nanometric dimensions. Study of nano-precipitates within the steel microstructure is of great interest, and yet it is often difficult to directly characterize features of nano-scale dimensions within steel microstructure. The main techniques used for studying these precipitates are extraction replica and atom probe which have their own limitations.

Previously, using a combination of TEM-based quantitative techniques, we showed that it is possible to correlate the extra strength of V-added HSLA steels to their microstructure [1]. Similarly in the current work, through using Super-EDS in studying high strength low alloy (HSLA) pipeline steels and their welds, we showed that elemental mapping could provide a relatively fast and convenient approach, when verified by electron diffraction techniques, for phase identification. Combination of EDS mapping, electron diffraction and electron energy loss spectroscopy (EELS) techniques provided us with a powerful tool to correlate mechanical properties of X70 steel welds and heat affected zones (HAZ) to their microstructural evolution.

In Fig. 1, a STEM-HAADF micrograph of an API X70 steel is shown. Elemental maps in C and D show $\mathrm{Ti}(\mathrm{CN})$ and $\mathrm{Nb}(\mathrm{CN})$ precipitates. We found that the carbonitride usually consists of a $\mathrm{Ti}(\mathrm{CN})$ core where $\mathrm{Nb}(\mathrm{CN})$ nucleates heterogeneously. Using electron diffraction we showed that the Mn-rich phase formed at the grain boundary was in fact retained-austenite as seen in the CBED pattern in Fig. 1F. Moreover, EDS mapping provided us with a powerful tool to study the structure of these, often complex, precipitates in both the base metal and the heat affected zones (HAZ) of HSLA welds. Combined with EELS log-ratio thickness measurement technique, EDS maps were used to measure number density of strength-contributing nano-scaled precipitates. We found a significant decrease in number density of these precipitates in HAZ. Figure 2 is an example of $\mathrm{Ti}-\mathrm{Nb}(\mathrm{CN})$ complex phases found in $\mathrm{HAZ}$ of an $\mathrm{X} 70$ pipeline steel. It appears that during the process of heating $\mathrm{Nb}(\mathrm{CN})$ dissolves within the matrix and subsequently re-nucleates on the overgrown cubic $\operatorname{Ti}(\mathrm{CN})$ precipitates during cooling in the HAZ, causing a decrease in the overall number density of the strengthening precipitates. The decrease in the number density of strengthening precipitates was linked to the loss of strength in HAZ. [2]

\section{References:}

[1] S Nafisi, B Shalchi Amirkhiz, F Fazeli, M Arafin, R Glodowski and L Collins, ISIJ International (2016), p.154 
[2] The authors acknowledge funding from the Canadian federal government Program of Energy Research and Development (PERD).
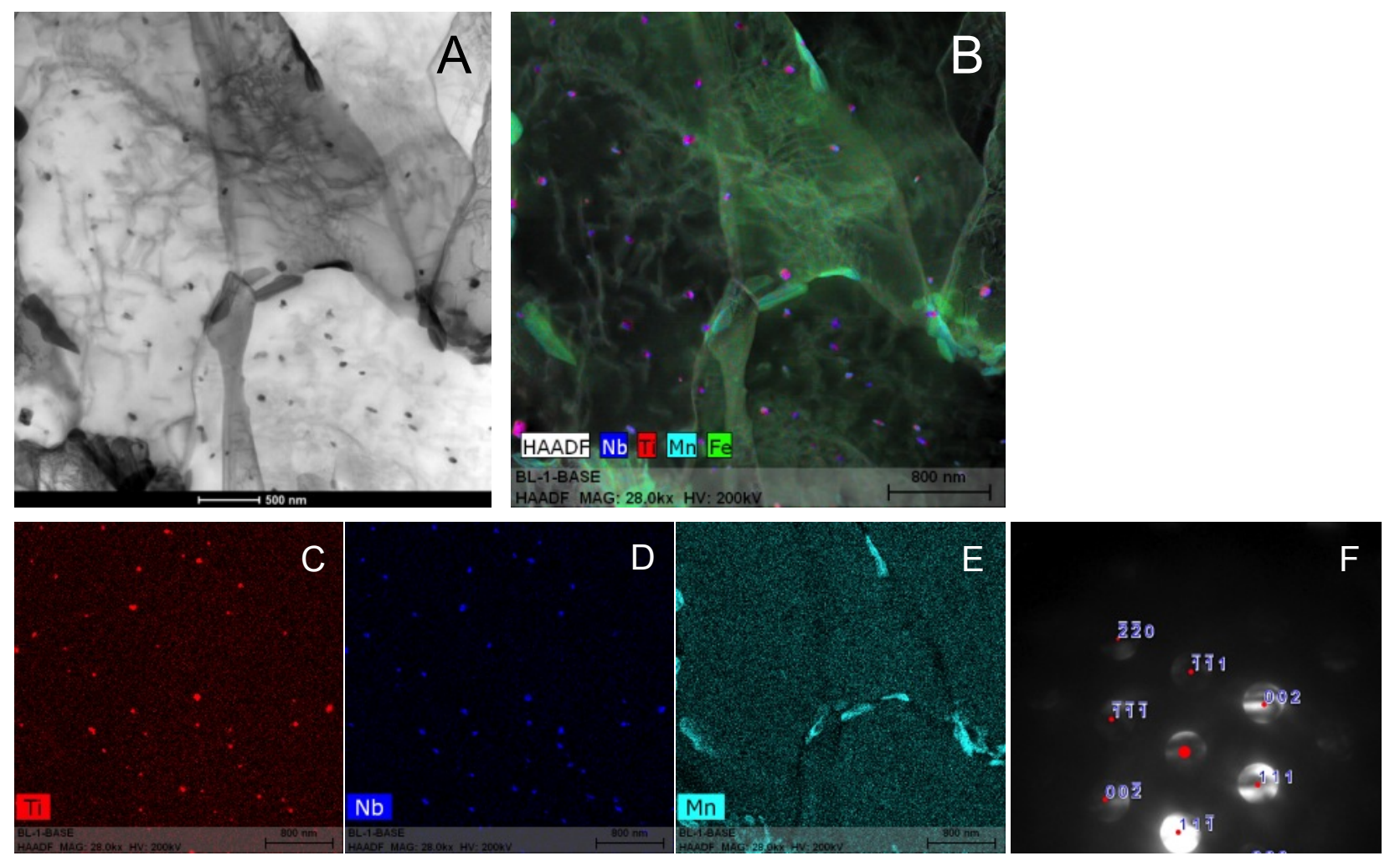

Figure 1. STEM-HAADF (A) showing microstructure of an API X70 steel, B is a combination EDS elemental map overlaid on the HAADF, C-E are EDS elemental maps of $\mathrm{Ti}, \mathrm{Nb}$ and $\mathrm{Mn}$, respectively, and $\mathrm{F}$ is a CBED pattern from one of the Mn-rich phases, showing gamma along [ $\left.\begin{array}{lll}\overline{1} & 1 & 0\end{array}\right]$ viewing direction.

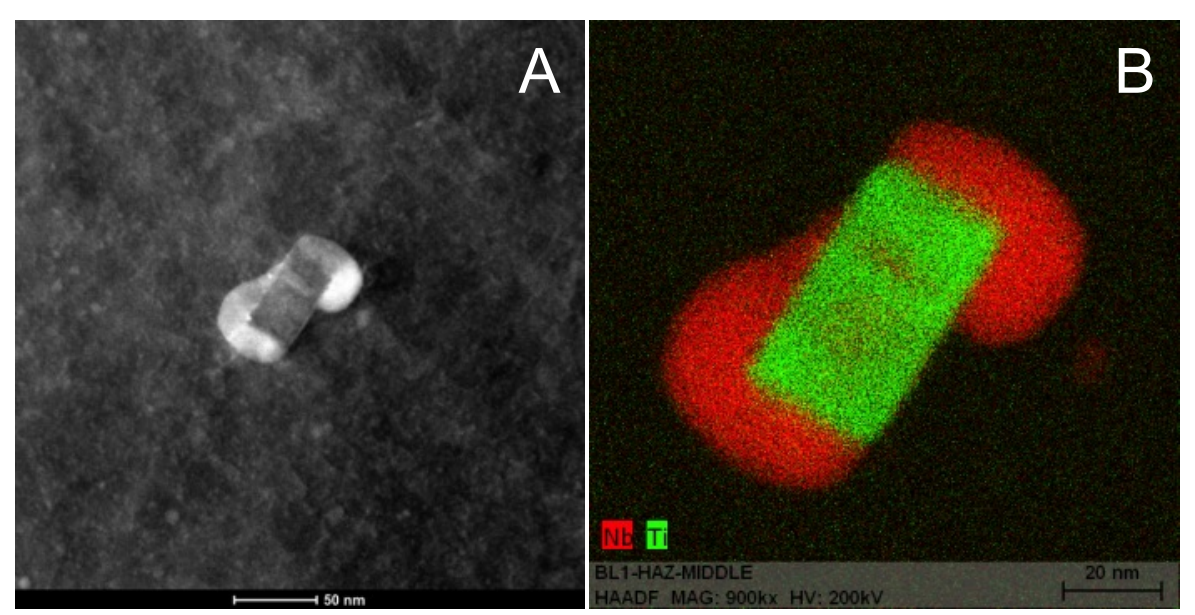

Figure 2. STEM-HAADF (A) and corresponding combination EDS elemental map (B) of an overgrown $\mathrm{Ti}(\mathrm{CN})$ precipitate acting as nucleation site for $\mathrm{Nb}(\mathrm{CN})$ in the $\mathrm{HAZ}$ of an API X70 weld. 